\section{Cultura y Turismo: Valorar, Preservar la Memoria Histórica y Artística del Centro Histórico de Lima}

\author{
Culture and Tourism: Valuing and Preserving the Historical \\ and Artistic Memory of the Historical Center of Lima World \\ Heritage Site
}

\begin{abstract}
RESUMEN
El mundo experimenta cambios acelerados, la globalización surge de manera determinante por lo cual urge la necesidad de hablar de cultura y turismo, principales herramientas que permitirán el desarrollo de la ciudad a través del ingreso de visitantes que llegan motivados y atraídos en busca de nuevas experiencias culturales. El turismo es una actividad que se promueve con mayor interés. Hace unos años surgieron calificativos como "Lima la fea", "Lima caótica" y "Lima tugurizada" pero nuestra ciudad, se ha transformado en una "Lima linda" de gran atractivo en estos últimos 15 años; las alcaldías de turno han descubierto su riqueza histórica y artística con sus más de 600 monumentos ubicados en el Centro Histórico de Lima y Rímac, declarado por la Unesco el año de 1991 como Patrimonio de la Humanidad. Este artículo tiene por objetivo dar a conocer la importancia de preservar y valorar los monumentos de este importante eje turístico.

Palabras claves: Turismo; cultura; preservar; valores; patrimonio.
\end{abstract}

\begin{abstract}
The world undergoes accelerated changes, globalization emerges in a decisive way, which is why there is an urgent need to talk about culture and tourism, the main tools that will allow the development of the city; it is possible with the entrance of visitors who arrive motivated and who are attracted in searching new cultural experiences .Tourism is an activity that is promoted with greater interest. Some years ago, qualifying language emerged describing Lima as "Lima, the ugly", "Lima the chaotic" and "Lima the slum" but our city has been transformed into a "Beautiful Lima", a place of great appeal in the last 15 years. Mayors nowadays have discovered the historical and artistic wealth that it possesses, having more than 600 monuments that are located in the Historical Center of Lima and Rimac, declared by Unesco in the year 1991 as World Heritage. This article aims to raise awareness of the importance to preserve and value the monuments that host this important tourist axis.

Keywords: Tourism; culture; preserve; values; heritage.
\end{abstract}

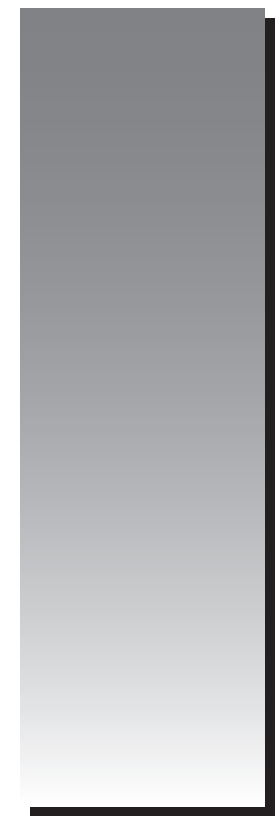

Gladys Moscoso Zelaya

gmoscosoz@unmsm.edu.pe

Universidad Nacional Mayor de San Marcos, Facultad de Ciencias Administrativas. Lima, Perú 


\section{INTRODUCCIÓN}

El centro histórico se ubica en el distrito de Lima Metropolitana, región Lima considerado patrimonio de la humanidad, llamada también Ciudad de los Reyes, lugar donde se encuentra la Plaza Mayor, siendo este un ambiente urbano monumental que alberga en sus alrededores una serie de edificaciones históricas, que forman parte de la trayectoria del virreinato, escenario de diversos acontecimientos durante el siglo XVI con la llegada de Francisco Pizarro, fundada la ciudad de Lima el 18 de enero del año 1535, se demarca el terreno del denominado Damero de Pizarro, con los conquistadores que llegaron a estas nuevas tierras, con el apoyo de Diego de Agüero, se asigna los primeros solares a los nuevos vecinos de Lima. Esta Zona Monumental alberga una serie de construcciones, de arquitectura religiosa constituida por iglesias y conventos, que se convierten en lugares de evangelización, se pueden observar otros edificios como palacios, casonas, plazuelas y pasajes de uso privado denominado arquitectura civil y pública.

Chaos (2009) puede comparar que "en Latinoamérica los Centros Históricos, están conectados por plazas y plazuelas por calles irregulares debido a la presencia de construcciones prehispánicas y esta a su vez se constituye en una arquitectura monumental y domestica cuya influencia de trazo medieval urbano son similares a las de Europa", (p.78)

Lima colonial sobrevive conservando los nombres de sus calles antiguas evidencia de algunos rótulos que fueron colocados en el siglo $\mathrm{XX}$, con placas en azulejos ubicados en las paredes externas de las calles, que nos recuerda sus antiguos nombres.

La valoración patrimonial no es el fin en sí mismo, sino que a través de ella una sociedad puede lograr reconocer su capacidad creativa y transformadora para promover su propio desarrollo. Es importante en este contexto evidenciar que el patrimonio se crea cotidianamente en la apropiación y uso de sus espacios, siendo el centro histórico, como espacio público por excelencia uno de los más importantes en las ciudades (Vergara, 2009, p.4)
El mayor problema que afrontó Lima fue el crecimiento urbanístico de manera desordenada, con el desplazamiento de los pobladores de la sierra de nuestro país en la década del 70 en busca de mejorar su calidad de vida en la capital, las casas construidas para dos familias se convirtieran en multifamiliares, tugurizando espacios históricos comprometiendo dichas edificaciones, considerados monumentos históricos, para la década de los 80`s, la plaza Mayor se convirtió en escenario de muchos acontecimientos y encuentro del comercio ambulatorio, uno de los cambios más notables se realizó en la década del noventa con el alcalde ya desaparecido Alberto Andrade Carmona que logro recuperar la Plaza Mayor y los alrededores devolviéndole a Lima la oportunidad de brillar nuevamente, hoy la antigua calle Polvos Azules es Chabuca Granda, donde se dio el primer paso de cambio y recuperación del Centro Histórico de Lima. Ahora en pleno siglo XXI, queda pendiente dentro de los proyectos del municipio la recuperación de la casa de las columnas, ubicada en el Jirón Conde de Superunda al costado de la Casa de Osambela que a pesar de existir un Plan Maestro del Centro Histórico no se puede recuperar dicho edificio que formo parte de la propiedad de los Dominicos, por resistencia a ser reubicados.

Vergara (2009) El patrimonio cultural "está formado por los bienes susceptibles de valor que la historia en todas sus épocas le ha legado a una nación y, por aquellos que en el presente se crean y a los que la sociedad les otorga una especial importancia histórica, científica, simbólica o estética, p. 6

Mantecon (2003) establece:

México es uno de los países que más invierte en la recuperación y conservación de su patrimonio, pero muchas edificaciones no están incluidas en la lista debido a que son edificaciones domésticas, determinaron que los bienes culturales actuales no deberían ser considerados por ser edificaciones pertenecientes a la clase urbana del pueblo. Consideraron dar valor no solo lo que es prehispánico sino también lo intangible o inmaterial, debe ser protegido de igual manera como las tradiciones y las lenguas, ( p.4) 
A diferencia de México. Nuestra capital Lima tiene como objetivo recuperar un bien inmueble ofreciendo a las familias reubicarlas en espacios muy cerca al lugar que ocuparon por más de 30 o 40 años. Con el desalojo de estos monumentos históricos, se realizan estudios de factibilidad e intervención, siendo la conservación y recuperación de éstos monumentos un trabajo coordinado con la municipalidad bajo la supervisión del Ministerio de Cultura.

Así mismo la Municipalidad lanzó campañas en los periodos municipales de Alberto Andrade y de Susana Villarán el programa "Adopte un balcón", en el cual la empresa o entidad financiera aporta el dinero para recuperar un balcón, bajo la supervisión y participación del Ministerio de Cultura.

\section{Delgadillo (2009) hace referencia:}

La relación que existe entre el patrimonio urbano y el turismo cultural, determinando sus ventajas y desventajas haciendo un análisis a quien le pertenece el patrimonio edificado y quien se aprovecha de su herencia cultural, que han sido reconocidos por la UNESCO como patrimonio de la humanidad como legado cultural de la Ciudad de México, (p.70)

Una situación similar surge en Lima centro histórico cuando hacemos un recorrido por el Cercado y el Rímac, nos recuerdan que cada lugar tiene su momento histórico. Han pasado siglos para que la participación del Estado de la mano de la población se analice y se revaloren estos edificios domésticos como importantes monumentos que por sí solos narran una historia prehispánica, colonial y la enlazan a la modernidad.

Según Vera (2015) destaca, "al mismo tiempo, con el objetivo de posicionarlas como productos dentro del mercado mundial, en tanto ciudades de negocios, de turismo, cultura o innovación se están desarrollando marcas de ciudad que condensan imágenes y valores para la transformación del modelo económico urbano." (citado en Lury, 2007)"

La Marca cultural se posesiona en la mente del consumidor nacional y receptivo a través de imágenes, valores identificando una cronología histórica que permita a través de museografía involucrar al visitante de manera que interprete el turismo cultural como parte de las emociones de conocimientos previos e inducir la toma de conciencia.

El artículo presenta la recuperación en el reconocimiento de los valores que se evaluaran para preservar el Centro Histórico de Lima como Patrimonio de la Humanidad y dividido en: valores históricos prehispánicos, valores tradicionales y religiosos, valores gastronómicos, valores arquitectónicos y artísticos, valores históricos republicanos y contemporáneos.

\section{OBJETIVO}

El artículo tiene como objetivo identificar los valores que permita crear conciencia con los cuales preservar los monumentos históricos y artísticos del centro de la ciudad que forman parte del patrimonio de la humanidad, planteada a su vez por Recondo (2009) Nos dice que los centros históricos urbanos constituyen estructuras integrantes de la ciudad que sobresalen por la concentración de valores culturales asociados en el desarrollo y expresados en el urbanismo y en su arquitectura.

Se ha determinado estructurar la principal fuente de información a través de valores divididos y explicados generando la importancia de estas en el tiempo, el conocimiento permita su preservación y posterior puesta en valor.

\section{ARGUMENTACIÓN}

Hablar de valores que se deben tener en cuenta para la preservación de edificaciones coloniales, llama a la reflexión de este siglo cuando vemos desaparecer monumentos por falta de criterio y preocupación por lo nuestro, en estos últimos años se ha visto cerrar museos debido a que sus estructuras están débiles y necesitan reforzar ya que estas son edificaciones coloniales y republicanas adaptadas para museos, al cerrar sus puertas se pierde el contacto con sus colecciones, urge la necesidad de iniciar haciendo una descripción y reconocimiento para valorar este gran legado cultural.

\section{Valores históricos prehispánicos}

Cuando se habla de la valoración de los antecedentes prehispánicos, remonta la historia relacionada al agua de los ríos, supieron vencer 
las zonas desérticas para que luego pudieran dominar y desarrollar las culturas pre Incas e Incas. Por los años 1460, mucho antes de la llegada de los españoles se desarrolló la cultura Inca en este noble valle del Rímac aprovechando las aguas del Rio Guatica y Surco, siendo su gobernador un curaca llamado Taulichusco administrador de aguas que le toco recibir a Francisco Pizarro, y en ese terreno que era una plaza principal prehispánica de forma triangular, convertida hoy en Plaza Mayor de Lima, entonces somos un país con historia no nacemos con la llegada de los españoles, sino un país y ciudad con raíces profundas con una cultura desarrollada y civilizada, pero en disputa por el poder de tierras, por esta razón se debe afianzar este legado y difundirlo a las nuevas generaciones, conocer la información que guarda la Pileta de la Plaza Mayor que conectaba con piletas cercanas que fueron estratégicamente ubicadas para abastecer de agua a la población limeña durante el virreinato.

\section{Valores Tradicionales y Religiosas}

Continuar con las tradiciones que forman parte de las procesiones, celebraciones religiosas y costumbristas. Como la celebración del aniversario de Lima cada 18 de enero, las procesiones que se desarrollan en el mes de octubre con la procesión del Señor de los Milagros, que a través del tiempo ha crecido y traspasado fronteras dicha festividad que se inició con el culto a una pintura mural pintada por un negro angoleño, imagen que no pudo ser destruida ni por terremoto ni por la mano del hombre. Cuyo registro será planteado en el análisis del Santuario de las Nazarenas donde se dio inicio a este valor tradicional y religioso.

\section{Valores Gastronómicos}

Las costumbres gastronómicas de Lima de antaño, trabajo de investigación que se recupera con los bocetos de Pancho Fierro pintor costumbrista que plasma en sus acuarelas a los vendedores ambulantes como chicheras, bizcocheros, champuseras rescatando los dulces limeños virreinales, como revolución caliente, melcochas, suspiros, mazamorras. Con el fin de preservar este valor en la actualidad que conecta y forma parte de la actividad turística con la ejecución de ferias gastronómicas como parte de los tours, parada obligada para el deleite de los visitantes que se trasladan hacia Chabuca Granda a probar los deliciosos dulces limeños, complementado luego con la visita a la Casa de gastronomía.

\section{Valores arquitectónicos y artísticos}

Declarada por la UNESCO a Lima como patrimonio de la Humanidad., por albergar un determinado número de monumentos históricos en el perímetro de Lima y Rímac, casi 600 monumentos, entre Basílicas, iglesias, capillas, conventos, palacios, casonas, plazas, plazuelas, paseos y alamedas con sus bustos y esculturas.

Nuestra capital alberga una arquitectura de diversos estilos como el barroco, rococó y neoclásico que conforma el patrimonio inmueble y estos a su vez albergan el patrimonio mueble, como lienzos, muebles y esculturas coloniales, de estilos diversos, además el centro histórico cuenta con importantes monumentos religiosos como Catedral de Lima, Basílica de San Francisco, Basílica del Rosario, Iglesia San Pedro, San Agustín, La Merced, Jesús María y José, parroquia de San Sebastián, Santuario de Santa Rosa, Iglesia de la Recoleta, Sagrado corazón de Jesús, pertenecientes a las principales órdenes religiosas.

\section{Valores históricos Republicanos y contem- poráneos}

El Centro Histórico está constituido por edificaciones republicanas y contemporáneas que conforman gran parte de los inmuebles que rodean la plaza Mayor, como Palacio Municipal, Palacio de Gobierno, Palacio Arzobispal, Palacio Legislativo, Club Unión y los Portales con sus dos pasajes Santa Rosa y Pasaje Olaya.

En nuestra experiencia en tours temáticos peatonales por rutas definidas en dónde. Pinassi (2012) "menciona que la metodología, el Inventario de Patrimonio Arquitectónico y Urbano en sus diferentes ámbitos jurisdiccionales, se consideran elementos fundamentales de análisis. Por ello será la observación nuestro instrumento in situ, para recopilar y analizar documentos históricos a través de una ficha inventario que permita completar información relevante de los monumentos históricos, para desarrollar un corredor turístico donde se dé a conocer el patrimonio cultural. 
Cultura y Turismo: Valorar, Preservar la Memoria Histórica y Artística del Centro Histórico de Lima

Se ha elaborado una ficha técnica de registro, para recopilar información necesaria que podrá ser utilizada para rescatar datos cuyo contenido sea fundamental en el logro de la puesta en valor de la historia y arte de los monumentos del centro histórico de Lima.

\section{CONCLUSIONES}

El presente artículo rescata la importancia que a través de la investigación trasmite el legado cultural a futuras generaciones, permite crear conciencia en la población de conocer y valorar su patrimonio histórico cultural.

Tabla 1

Cultura y turismo: valorar y preservar la memoria histórica y artística del centro histórico de lima patrimonio de la humanidad. Ficha técnica $n^{\circ} 1$ de monumentos históricos

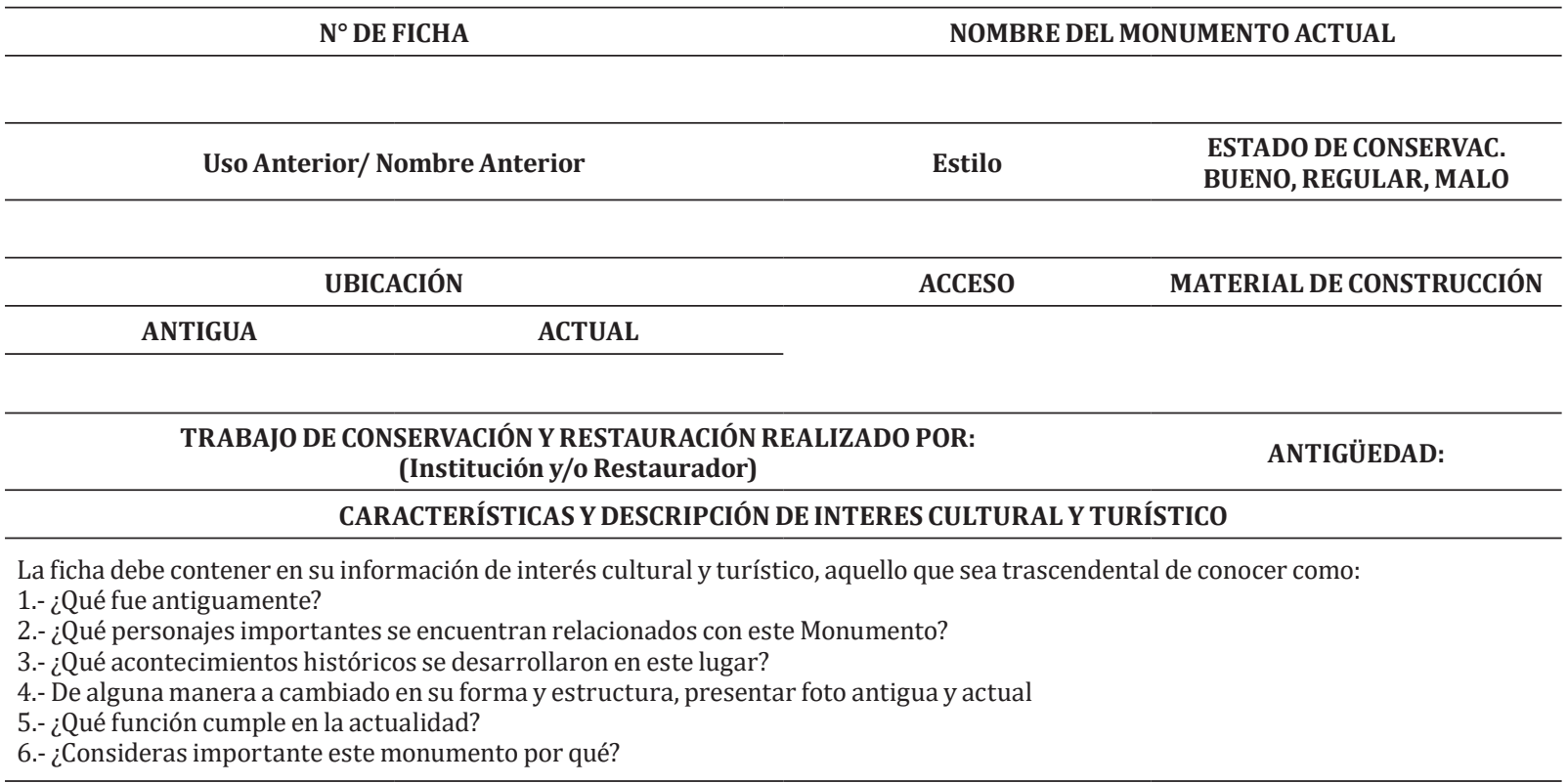

\section{FOTOGRAFIA ACTUAL/GRUPAL}

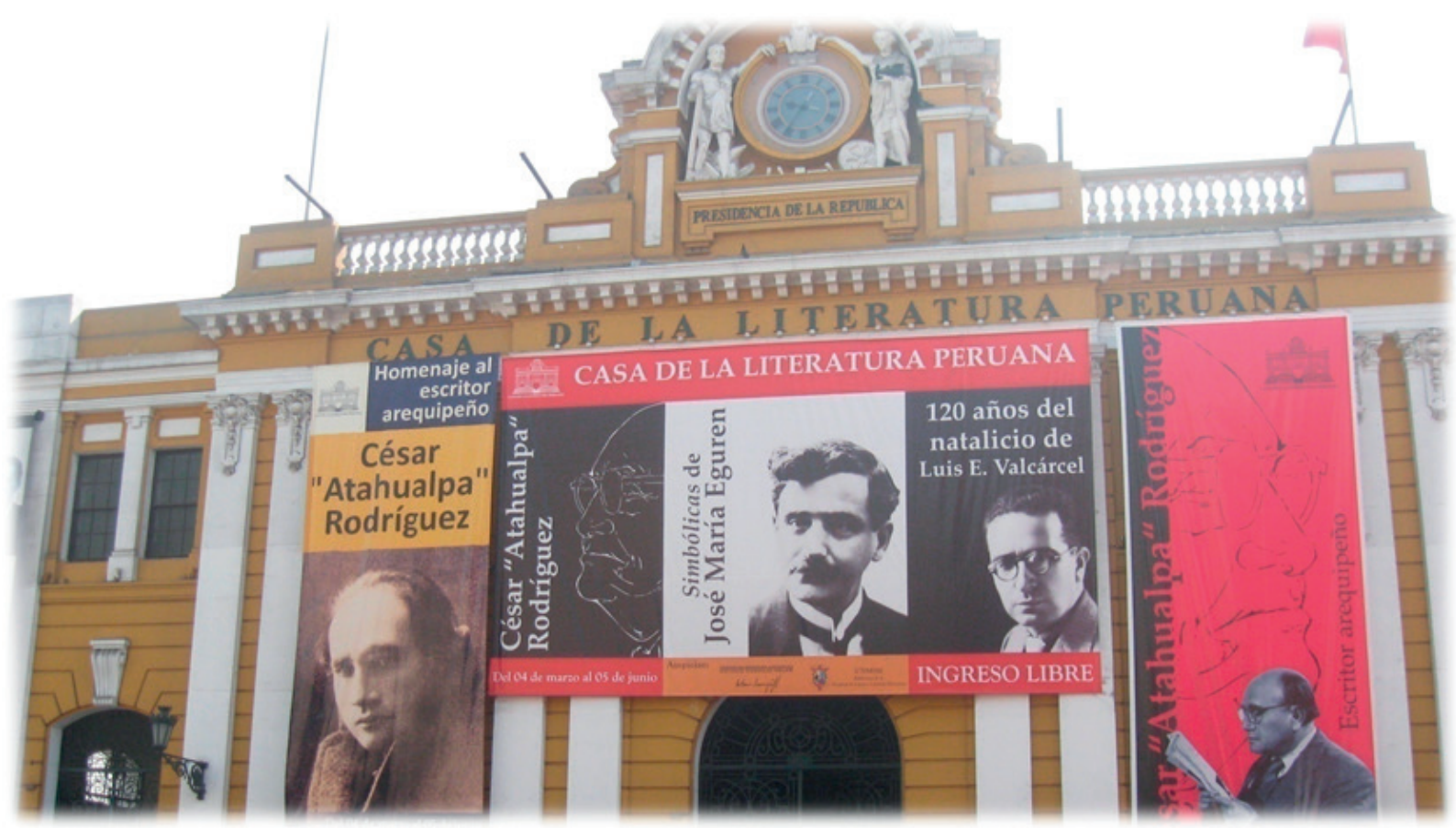

Fuente: Elaboración propia 
A su vez permite al visitante conocer e identificar su entorno para generar un valor y compromiso que lo motive a difundir y a crear conciencia en preservar los monumentos históricos.

El reordenamiento municipal actual del centro histórico de Lima permitirá a la población que llega al centro de la ciudad ver los cambios en cuanto a limpieza, seguridad y reordenamiento vehicular, brinde al visitante la confianza de seguridad a través de las vías peatonales, podrán apreciar mejor la arquitectura de los edificios históricos y de esta manera lograr una mejor interpretación del entorno.

El registro en fichas es un análisis y diagnóstico de la situación de estos importantes edificios, existe la necesidad de registrar y fotografiar estos monumentos si queremos lograr un turismo cultural sostenible.

Se tomó en cuenta el Perfil del Turista extranjero del año 2017, fuente importante que permite evaluar el porcentaje de turistas y sus actividades que desarrolla en Lima de acuerdo a su permanencia y su preferencia cultural, se analizó de acuerdo al consolidado del Perfil, documento elaborado por Promperú sobre visitantes extranjeros en Lima, documento que permitió establecer un diagnóstico de los visitantes y su preferencia por un turismo cultural, de acuerdo al cuadro.

En el último Perfil del Turista Extranjero del 2017, determino que el turista llega a Lima, en su permanencia, por un turismo cultural en un 91\% (Ver Tabla 2)

El centro de ciudad atrae un importante segmento de visitantes debido a que se encuentran las principales casonas, palacios, museos y conventos que ofrecen un recorrido adaptado a las necesidades del turista.

La permanencia del turista en Lima le permite la opción de elegir, lugares que cubran sus expectativas por cultura, se debe valorar Lima cercado, como una zona de alternativas culturales, considerada en un $63 \%$ elegido como uno de los principales lugares visitados, debiendo recalcar que el centro histórico se constituye la mayor oferta de tours para un turismo receptivo cultural (Ver Tabla 3).
Tabla 2

Las actividades que realiza el turista en Lima.

\begin{tabular}{lc}
\hline CULTURA & $91 \%$ \\
\hline Pasear caminar por la Ciudad & 86 \\
Visitar Parques /plazuelas de la Ciudad & 69 \\
Visitar, Iglesias/Catedral/ Conventos & 51 \\
Visitar Museos & 36 \\
City Tours guiado & 34 \\
Visitar Inmuebles histórico & 30 \\
Visitar Sitios arqueológicos & 43 \\
Visitar rutas gastronómicas & 6 \\
NATURALEZA & $\mathbf{4 4 \%}$ \\
Visitar Reservas naturales & 35 \\
Pasear por Ríos Cascadas y cataratas & 25 \\
Observación de flora & 18 \\
Observación de aves & 17 \\
Observación de mamíferos & 14 \\
Cuadro № 1 & \\
\hline
\end{tabular}

Fuente: Perfil del turista Extranjero 2017, Promperú, (p.2)

Tabla 3

Principales lugares visitados en lima metropolitana por el turista extranjero

\begin{tabular}{lc}
\hline PRINCIPALES LUGARES VISITADOS EN LIMA & $\%$ \\
METROPOLITANA POR EL TURISTA EXTRANJERO & $\%$ \\
\hline Miraflores & 69 \\
Lima & 63 \\
Barranco & 27 \\
San Isidro & 19 \\
Larco Mar & 10 \\
Callao & 9 \\
Huaca Pucllana & 6 \\
Surco & 6 \\
Chorrillos & 6 \\
Parque de las Aguas & 5 \\
Costa Verde & 5 \\
San Borja & 4 \\
La Molina & 3 \\
San Miguel & 3 \\
Parque del Amor & 3 \\
Cuadro № 2 & \\
\hline
\end{tabular}

Fuente: Perfil del turista Extranjero 2017, Promperú Consolidado, pág. 2

\section{REFERENCIAS BIBLIOGRÁFICAS}

Chaos, M. (2009). Centro Histórico de Camagüey Patrimonio de la Humanidad. Revista científica de Arquitectura y Urbanismo, 30(1), 78-79.

Delgadillo, V. (2009). Patrimonio Urbano Y Turismo Cultural En La Ciudad De México: Las Chinampas De Xochimilco Y El Centro Histórico. Andamios. Revista de Investigación Social, 6(12), 69-94. 
Mantecón, A. (2003). Los usos del patrimonio cultural en el Centro Histórico. Alteridades, 13(26), 35-43.

Pinassi, A. (2012). El Marketing Turístico del Patrimonio Cultural como Alternativa de Desarrollo del Centro Histórico de Bahía Blanca (Argentina). Diagnóstico de Situación. ROSA DOS VENTOS - Turismo e Hospitalidade, 4(1), 59-76.

PROMPERÚ. (2018). Perfil del Turista Extranjero 2017. Recuperado de https://www.promperu.gob.pe/TurismoIN/sitio/VisorDocumentos?titulo=Perfil $\% 20$ del $\% 20$ Turista $\% 20$ Extranjero\%202017\&url= /Uploads/perfiles_extranjeros/40/Book_PTE_2017_FINAL. pdf\&nombObjeto=PerfTuristaExt\&back=/TurismoIN/sitio/PerfTuristaExt\&issuuid=
Recondo, R. (2009). Matanzas, atractivos para un turismo cultural en el centro histórico. Revista de Arquitectura e Ingeniería, 3(1). Recuperado de http://www.redalyc.org/articulo. oa?id=193915041005

Vera, P. (2015). Estrategias patrimoniales y turísticas: Su incidencia en la configuración urbana. El caso Rosario, Argentina. Territorios, 17(33), 83-101. https://doi.org/10.12804/territ33.2015.04

Vergara, A. (2010). Centros Históricos: El Patrimonio como herramienta del Desarrollo Social. Memorias: revista digital de historia y arqueología desde El Caribe, ISSN 1794-8886, No. 11, 2010, 6(11), 4-14. 